\title{
Type 1 insulin-like growth factor receptor targeted therapies in pediatric cancer
}

\author{
Michael J. Wagner ${ }^{1}$ and Robert G. Maki ${ }^{2,3,4}$ * \\ ${ }^{1}$ Department of Medicine, Mount Sinai Medical Center, New York, NY, USA \\ 2 Department of Medicine, Mount Sinai School of Medicine, New York, NY, USA \\ ${ }^{3}$ Department of Pediatrics, Mount Sinai School of Medicine, New York, NY, USA \\ ${ }^{4}$ Department of Orthopedics, Mount Sinai School of Medicine, New York, NY, USA
}

\section{Edited by:}

Jeffrey Toretsky, Georgetown

University, USA

\section{Reviewed by:}

E. A. Kolb, Nemours, Alfred I. duPont Hospital for Children, USA

Corinne Linardic, Duke University

Medical Center, USA

\section{*Correspondence:}

Robert G. Maki, Department of

Medicine, Mount Sinai School of

Medicine, 1 Gustave L. Levy Place,

Box 1208, New York, NY 10029-6574,

USA.

e-mail: bobmakimd@gmail.com
Data from over 20 years ago demonstrated potential use for insulin-like growth factor (IGF) signaling modulators, specifically with IGF-1R antagonists, in a variety of pediatric and adolescent cancers, particularly in sarcomas. However, in spite of promising preclinical data, IGF-1R inhibitors have not had the success as single agents that was originally hoped for in clinical trials. Several potential mechanisms exist by which tumors are resistant to IGF-1R inhibitors. Notably, these resistance mechanisms are currently best understood in Ewing sarcoma and alveolar rhabdomyosarcoma. Various treatment schema have been proposed as a potential way to overcome this resistance. The use of IGF-1R inhibitors, mechanisms of resistance, and current ongoing clinical studies using IGF-1R inhibitors in pediatric cancers are reviewed here.

Keywords: insulin-like growth factor pathway, pediatric cancer, sarcoma, resistance mechanisms, IGF-1R

\section{INTRODUCTION}

The insulin-like growth factor (IGF) pathway regulates cellular growth, proliferation, and survival, and is important in the development of several cancers, including pediatric sarcomas, gliomas, neuroblastoma, and medulloblastoma. There are three main ligands that activate the IGF signaling cascade: IGF1, IGF2, and insulin. These ligands are bound to one of six binding proteins in circulation, IGFBP1-6. The IGF binding proteins, in particular IGFBP3, are implicated in modulating interactions between ligand and receptor. Some have negative effects on receptor signaling by competing for ligand. Others, notably IGFBP2 and IGFBP5, amplify IGF signaling (reviewed in Grimberg and Cohen, 2000). Higher levels of extracellular IGFBP3 are thought to decrease signaling via IGF-1R even independent of ligand (Ricort and Binoux, 2001). IGF binding proteins are also found intracellularly. The IGF binding proteins have a wide range of functions and have been implicated in signaling cascades other than IGF signaling (reviewed in Grimberg and Cohen, 2000; Weroha and Haluska, 2012). Further research is needed to elucidate their many biological roles and their precise role in cancer development.

There are two IGF receptors, IGF-1R and IGF-2R, with IGF$1 \mathrm{R}$ as the more important positive regulator of the IGF initiated cascade as it is the only one with an intracellular kinase domain (De Meyts and Whittaker, 2002). In contrast to the activating effects of IGF-1R signaling, IGF-2R is thought to be a negative regulator of IGF signaling by binding extracellular IGF2 (Ghosh et al., 2003). Unlike most other receptor tyrosine kinases, IGF-1R and insulin receptors exist as dimers prior to ligand binding. These receptors can act as either homodimers or a variety of heterodimers. Either variation can take part in tumorigenesis.

Binding of ligand to IGF-1R leads to autophosphorylation of the intracellular domain and recruitment of adapter proteins, ultimately leading to activation of a signaling cascade that can include modulation of PI-3-kinase/AKT/mTOR and Ras/Raf/MAPK, leading to cell proliferation (reviewed in Pollack, 2008; Rikhof et al., 2009; Maki, 2010).

In spite of very encouraging preclinical results, initial clinical studies of IGF-1R antagonists as a single agent have not demonstrated the results that were initially anticipated in clinical trials. Several potential mechanisms exist by which tumors are resistant to IGF-1R inhibitors. Various treatment schema have been proposed as a potential way to overcome this resistance. The preclinical data in pediatric cancers, mechanisms of resistance, and current ongoing clinical studies using IGF-1R inhibitors are reviewed here.

\section{ROLE OF IGF-1R IN PEDIATRIC CANCER EWING SARCOMA}

Ewing sarcoma is the second most common bone cancer in children and adolescents. It can also occur in soft tissue. IGF-1R signaling must be intact for Ewing sarcoma cell lines to proliferate (Yee et al., 1990). Ewing sarcoma is characterized by IGF pathway activating translocations of the EWSR1 gene. The most common translocation, found in approximately $85 \%$ of Ewing Sarcomas, is $\mathrm{t}(11 ; 22)$ EWSR1-FLI1. The EWSR1-FLI1 gene product directly inhibits the IGFBP-3 promoter (Prieur et al., 2004). Since IGFBP-3 sequesters IGF-I from circulation (Lee and Rechler, 1996), the decreased levels of IGFBP-3 that result from the translocation may increase the bioavailability of IGF-I, thus promoting tumor growth (Kim et al., 2009). Initial preclinical testing showed that murine monoclonal antibody alphaIR3, an IGF-1R antagonist, slows in vivo growth of Ewing sarcoma cells in mice (Scotlandi et al., 1998). Testing by the Pediatric Preclinical Testing Program further demonstrated that growth of some Ewing sarcoma cell 
lines is inhibited by IGF-1R inhibition (Kolb et al., 2008, 2011). IGF-1R blockade can also be combined with other agents, specifically vincristine, doxorubicin, or imatinib for synergy (Martins et al., 2006).

\section{ALVEOLAR RHABDOMYOSARCOMA}

Rhabdomyosarcomas are divided into two histological subtypes: embryonal, which represents about $70 \%$ of all rhabdomyosarcoma, and alveolar, which represents about 30\%; pleomorphic rhabdomyosarcoma appears to be a genetically distinct sarcoma that occurs principally in adults and not in children. Although IGF activation has been implicated in driving the tumorigenicity of both rhabdomyosarcoma types, the molecular characterization of alveolar rhabdomyosarcoma (ARMS) is better understood and is therefore the focus here.

Alveolar rhabdomyosarcoma is associated with a fusion protein resulting from translocations in the $P A X 3$ or $P A X 7$ genes and FOXO1. The fusion protein activates the IGF-1R promoter, resulting in increased receptor expression (Ayalon et al., 2001; Xiao et al., 2002). AKT signaling secondary to up-regulation of IGF-1R has also been implicated in having an inferior outcome in ARMS patients with stage III disease, suggesting a way to risk stratify patients (Petricoin et al., 2007). As in Ewing sarcoma, rhabdomyosarcoma cell lines have demonstrated sensitivity to IGF-1R inhibition (Kolb et al., 2008, 2011).

\section{OSTEOSARCOMA}

Osteosarcoma is the most common bone cancer in children (Mirabello et al., 2009). Osteosarcoma cell lines are dependent on IGF-1 via IGF-1R for in vitro growth (Kappel et al., 1994), and IGF-1R expression has been associated with poor prognosis (Wang et al., 2012). Nearly 20 years after that first observation, a mouse xenograft model using six different osteosarcoma cell lines demonstrated objective responses to R1507, a monoclonal antiIGF1R antibody, in vivo. Two cell lines were resistant to R1507 (Kolb et al., 2008, 2010).

\section{SYNOVIAL SARCOMA}

Synovial sarcoma has a peak incidence around adolescence and young adulthood (Spillane et al., 2000). It is characterized by $\mathrm{t}(\mathrm{X} ; 18)$ translocations which increase IGF pathway mediated signaling (Sun et al., 2006). Higher IGF-1R expression has also been associated with more aggressive synovial sarcoma (Xie et al., 1999). In preclinical studies, all of 15 synovial sarcomas tested showed significant IGF-II expression and 78\% showed activated IGF-1R. The IGF-1R inhibitor AEW541 had promising effects on proliferation. It also impaired cell migration (Friedrichs et al., 2008).

\section{WILMS TUMOR}

The role of IGF-1R signaling in the pathogenesis of Wilms tumor was proposed at least as early as 1989, when an anti-IGF-1R antibody slowed tumor growth in an in vivo model (Gansler et al., 1989). Although Wilms tumor is generally responsive to current treatment regimens, a relatively small proportion of patients will develop recurrence (Kalapurakal et al., 2004). Increased gene copy number of IGF-1R has been associated with recurrence, and in general with worse outcomes in Wilms tumor (Natrajan et al.,
2006). In spite of this evidence, little progress has been made studying the potential for IGF modulation in Wilms tumor. Initial results using Wilms tumor cell lines were promising (Houghton et al., 2010; Kolb et al., 2011), however technical difficulties growing and maintaining the cells in culture has hampered further research. Most recently, a mouse xenograft model in which cells from a Wilms tumor cell line were grown orthotopically within mouse kidney was used to show that AEW541, an IGF-1R inhibitor, reduced tumor growth (Bielen et al., 2012). It will be interesting to see if this finding can be translated to additional Wilms tumor cell lines, and in the clinic.

\section{NEUROBLASTOMA}

Neuroblastoma represents about $10 \%$ of pediatric malignancies and is the most common cancer in the first year of life. When high risk or metastatic, survival rates are on the order of $40-50 \%$ (Maris, 2010). Like several of the other tumor types discussed here, IGF signaling was implicated in the survival of neuroblastoma cells decades ago (El-Badry et al., 1989). Neuroblastoma cell lines are sensitive to the IGF-1R inhibitor BMS-536924 (Huang et al., 2009). Additionally, IGF-1R is a major determinant of the metastatic potential of neuroblastoma. Cell lines highly expressing IGF-1R were much more likely to develop osteolytic lesions when injected into mouse tibia compared to the same cells without IGF-1R. This is thought to be secondary in part to IGF-1 chemoattraction from bone stromal cells, allowing for a microenvironment that is conducive to tumor growth (van Golen et al., 2006). More recent laboratory studies showed that the addition of temozolomide to anti-IGF-1R agents improved both in vitro and in vivo responses compared to either agent alone. Interestingly, responsiveness to anti-IGF-1R murine antibody EM164 was not related to IGF-1R expression but was correlated with decreased AKT phosphorylation after treatment (Geoerger et al., 2010). Additional preclinical studies showed both single agent anti-IGF-1R activity and additive effects when combined with more standard chemotherapies in some neuroblastoma cell lines (Wojtalla et al., 2012).

\section{GLIOBLASTOMA}

Although usually seen in adults, glioblastoma does occur in children. Genetically, pediatric gliomas are more commonly associated with PDGFR-alpha aberrations compared to adult gliomas, which are more commonly associated with aberrations in EGFR signaling (Paugh etal., 2010). Gene amplification of IGF-1R has been shown in high grade pediatric gliomas (Bax et al., 2010; Schiffman et al., 2010). Preclinical studies combining IGF-1R inhibition with imatinib, which among other things inhibits PDGFR, showed hints of activity that are encouraging in this usually highly chemotherapy-resistant tumor type (Bielen et al., 2011).

\section{MEDULLOBLASTOMA}

Medulloblastoma is the most common brain malignancy in children, accounting for about $25 \%$ of all pediatric intracranial cancers (Northcott et al., 2012). IGF-1R is highly expressed in a majority of medulloblastoma, with one series reporting that $80 \%$ of medulloblastomas highly express IGF-1R (Del Valle et al., 2002). There were hints of antiproliferative activity of R1507 in 
some medulloblastoma cell lines. Interestingly, response did not seem to be correlated with level of IGF-1R expression (Wojtalla et al., 2012).

\section{GASTROINTESTINAL STROMAL TUMOR}

Gastrointestinal stromal tumors (GIST) occur in both children and adults. In adults, approximately $85 \%$ of GIST is at least partially driven by mutations in KIT or PDGFRA, a finding that led to the current imatinib- and sunitinib-based regimens used to treat most adult GIST (Demetri et al., 2002, 2006). On the other hand, pediatric GIST usually does not have the KIT and PDGFRA mutations that normally characterize adult GIST (Prakash et al., 2005; Janeway et al., 2007). This so-called wild type GIST is less responsive to imatinib and sunitinib (Janeway et al., 2009; Janeway and Pappo, 2012).

Insulin-like growth factor signaling dysregulation is also present in GIST from both age groups. Adult GIST is more commonly characterized by overexpression of IGF2. Pediatric GIST is more commonly associated with higher expression of IGF-1R (Agaram et al., 2008; Janeway et al., 2010; Italiano et al., 2012). The mechanism by which IGF-1R is overexpressed in these patients, and its clinical significance, remains unclear.

\section{MECHANISMS OF RESISTANCE RESISTANCE MECHANISMS AND PRECLINICAL DRUG COMBINATION STUDIES IN EWING SARCOMA}

Several different resistance mechanisms have been demonstrated in Ewing sarcoma. Garofalo et al. (2012) described common pathways through which Ewing sarcoma cell lines are resistant to multiple classes of IGF-1R antagonists. In all resistant lines tested, IGF-1R was down-regulated in spite of maintenance of the ability of treatment to lead to internalization and degradation of IGF-1R after exposure to the drug, suggesting that alternative signaling cascades independent of IGF-1R drive resistance. Up-regulation of insulin receptor (IR)-A and IGF-II was seen in multiple cell lines and seems to be one alternative signaling pathway allowing for resistance (Garofalo et al., 2012). Similarly, resistant cell lines also up-regulate the MAPK/ERK pathway. MAPK signaling was recently demonstrated to be a compensatory mechanism in Ewing sarcoma cell lines after exposure to an IGF-1R specific agent, particularly through phosphorylation of AKT (Huang et al., 2011). Finally, Potratz et al. (2010) showed that BMS-536924 resistant Ewing sarcoma cells up-regulated the activity of distal IGF-1R signaling components such as mTOR and ribosomal protein S6 (RPS6). Cells that did not up-regulate these distal proteins were sensitive to the IGF1R inhibitor. siRNA knockdown of RON (MST1R, macrophage stimulating 1 receptor tyrosine kinase), restored sensitivity in BMS-536294-resistant Ewing sarcoma cell lines by decreasing RPS6 activation. In preclinical studies, at least one Ewing sarcoma cell line demonstrated enhanced response with IMC-A12 combined with rapamycin (Kolb et al., 2012).

\section{RESISTANCE MECHANISMS AND PRECLINICAL DRUG COMBINATION STUDIES IN ARMS}

The observation of paradoxical activation of AKT with mTOR inhibitors led to the development of combination treatment using pretreatment with IGF-1R inhibitors in addition to mTOR inhibitors (Wan et al., 2007). In vivo studies combining IGF-1R inhibitors with rapamycin resulted in more sustained antitumor effect compared to either agent alone in a mouse xenograft model (Cao et al., 2008). In resistant ARMS cell lines, Huang et al. (2010) demonstrated different resistant mechanisms for different cell lines. In Rh41-807R cells, which are resistant to a small molecule dual-kinase inhibitor blocking both IGF-1R and IR, PDGFRA up-regulation proved to be the underlying cause of resistance. In Rh41-MAB391R cells, resistant to MAB391, an IGF-1R blocking antibody, AXL overexpression seems to be the culprit leading to resistance, although this cause and effect relationship is less clear.

IGF-1R-Her2 heterodimerization is another mechanism by which RMS cells develop resistance to IGF modulating agents. In vitro studies with ARMS cells demonstrated that co-treatment with NVP-AEW541, an IGF1R inhibitor, combined with lapatinib, a HER2 antagonist, reduced the phosphorylation of IGF-1R and consequently decreased IGF mediated signaling in cells resistant to IGF-1R modulators alone (Abraham et al., 2011).

\section{RESISTANCE MECHANISMS AND PRECLINICAL DRUG COMBINATION STUDIES IN OSTEOSARCOMA}

The two cell lines that were resistant to R1507 in vivo, mentioned previously, both had evidence of MAPK phosphorylation through mTOR signaling, representing a possible escape mechanism in these lines after exposure to IGF-1R inhibition (Kolb et al., 2010). More recently, two osteosarcoma cell lines were among the lineages that showed enhanced activity when exposed to both IGF-1R antibody with rapamycin (Kolb et al., 2012). Ultimately, further studies are needed to assess the role of IGF modulation as a potential treatment modality for osteosarcoma.

\section{CLINICAL TRIALS}

In clinical studies with IGF-1R antagonists alone, responses in patients were seen in some Ewing sarcoma patients (Table 1) and in isolated cases in patients with other cancers. Although some of these responses were quite dramatic, as a whole these results and the relatively small overall response rates are disappointing considering the plethora of promising preclinical data that preceded the early clinical trials.

As a result of our relatively new understanding of the role of alternative signaling pathways providing an avenue for

Table 1 | IGF-1R inhibitors in Ewing sarcoma (adapted from

Maki, 2012).

\begin{tabular}{llll}
\hline Reference & Drug & Phase & Response (\%) \\
\hline Pappo etal. (2011) & R1507 & II & $11 / 115(9.6)$ \\
Juergens et al. (2011) & Figitumumab & I-II & $15 / 106(14)$ \\
Malempati etal. (2012) & Cixutumumab & I-II & $1 / 35(2.9)$ \\
Tap etal. (2012) & Ganitumab & II & $1 / 18(5.6)$ \\
Tolcher etal. (2009) & Ganitumab & I+tail & 2/12 (16) \\
Olmos etal. (2010) & Figitumumab & I-II & $2 / 16(12)$ \\
& & TOTAL & $41 / 312(13)$
\end{tabular}


Table 2 | Clinical trials with IGF-1R antagonists including pediatric patients.

\begin{tabular}{|c|c|c|c|c|c|}
\hline Trial \# & Drug & Phase & Sponsor/PI & Status & Publication \\
\hline NCT00560144 & $\mathrm{R} 1507$ & I & Hoffmann-La Roche & Completed & \\
\hline NCT00609141 & Cixutumumab & I & Suman Malempati, M.D. & Completed & Malempati etal. (2012) \\
\hline NCT00976508 & Figitumumab + Pegvisomant & I & Pfizer & Terminated & \\
\hline NCT01182883 & Cixutumumab + Temsirolimus & I & Dennis D Hickstein, M.D. & Withdrawn prior to enrollment & \\
\hline NCT00617890 & SCH 717454 & $\|$ & Merck & Active, not recruiting & \\
\hline NCT00642941 & $\mathrm{R} 1507$ & $\|$ & Hoffmann-La Roche & Active, not recruiting & Pappo et al. (2011) \\
\hline NCT0161479 & Cixutumumab+Temsirolimus & $\|$ & Lars M. Wagner, M. D. & recruiting & \\
\hline
\end{tabular}

IGF-1R antagonist resistance, canonical AKT activation has been emphasized as a possible target for clinical development of combination regimens. Clinical studies are currently underway combining IGF-1R inhibitory agents with mTOR inhibitors. Some encouraging responses were seen in these preliminary studies. In a phase I dose-expansion trial combining the IGF-1R inhibitor cixutumumab and mTOR inhibitor temsirolimus, 7 of 20 patients had either stable disease or responses by RECIST criteria (35\%), and $29 \%$ had tumor regression. Interestingly, one of the six patients who had previously developed resistance to a different single agent IGF1R inhibitor had a complete response (CR) in this study (Naing et al., 2012). A second phase I study combining an IGF$1 \mathrm{R}$ inhibitor and mTOR inhibitor, figitumumab and everolimus, also saw cases of promising responses. This time, the most pronounced response was in a patient with solitary fibrous tumor (Quek et al., 2011).

At least one phase II study is seeking to expand on the findings of the phase I studies combining IGF-1R and mTOR targeted agents. Here, cixutumumab and temsorilimus had PFS rates of $32-42 \%$ after 12 weeks. Patients with Ewing sarcoma in the study had a response rate of $20 \%$, with responses seen also in osteosarcoma, chondrosarcoma, and solitary fibrous tumor patients. Interestingly, in this study there was no clear correlation between biochemical markers of IGF-1R or mTOR pathway inhibition and clinical response (Schwartz et al., 2012).

\section{REFERENCES}

Abraham, J., Prajapati, S. I., Nishijo, K., Schaffer, B. S., Taniguchi, E., Kilcoyne, A., etal. (2011). Evasion mechanism to IGF1R inhibition in rhabdomyosarcoma. Mol. Cancer Ther. 10, 697-707.

Agaram, N. P., Laquaglia, M. P., Ustun, B., Guo, T., Wong, G. C., Socci, N. D., et al. (2008). Molecular characterization of pediatric gastrointestinal stromal tumors. Clin. Cancer Res. 14, 3204-3215.

Ayalon, D., Glaser, T., and Werner, H. (2001). Transcriptional regulation of IGF-I receptor gene expression by the PAX3-FKHR oncoprotein. Growth Horm. IGF Res. 11, 289-297.

Bax, D. A., Mackay, A., Little, S. E., Carvalho, D., Viana-Pereira, M., Tamber,

Most of the studies discussed above were not targeted to the pediatric population even though in many cases adolescents and young adults were included. Seven clinical trials were identified in the clinical trials database that were designed specifically to assess pediatric cancer, including patients less than 16 years old. Of those studies identified, three are ongoing and only one is actively recruiting patients as of early 2013 (Table 2).

\section{FUTURE DIRECTIONS}

In spite of the low response rates in most trials of IGF-1R inhibitors, the dramatic images seen in the patients who did respond encourage further research in this important signaling pathway. We are only beginning to understand the mechanisms by which cancers are resistant to IGF-1R targeted agents. Clinical trials aimed at overcoming this resistance are now underway, and more will surely aid in revealing which patients may best respond to IGF-1R therapies, which may require a combination regimen, and which may not respond at all. To date, very little is known in terms of predicting who may respond. Our understanding of the potential use of IGF-1R targeted agents is less well understood in children compared to adults. Although there is a plethora of basic science data both published and forthcoming, clinical data are still lacking. IGF-1R inhibitors remain a promising focus of investigation for pediatric cancer.

Cao, L., Yu, Y., Darko, I., Currier, D., Mayeenuddin, L. H., Wan, X., et al. (2008). Addiction to elevated insulin-like growth factor 1 receptor and initial modulation of the AKT pathway define the responsiveness of rhabdomyosarcoma to the targeting antibody. Cancer Res. 68, 80398048.

De Meyts, P., and Whittaker, J. (2002). Structural biology of insulin and IGF1 receptors: Implications for drug design. Nat. Rev. Drug Discov. 1, 769-783.

Del Valle, L., Enam, S., Lassak, A., Wang, J. Y., Croul, S., Khalili, K., et al. (2002). Insulin-like growth factor I receptor activity in human medulloblastomas. Clin. Cancer Res. 8, 1822-1830.
Demetri, G. D., van Oosterom, A. T., Garrett, C. R., Blackstein, M. E., Shah, M. H., Verweij, J., et al. (2006). Efficacy and safety of sunitinib in patients with advanced gastrointestinal stromal tumour after failure of imatinib: a randomised controlled trial. Lancet 368, 1329-1338.

Demetri, G. D., von Mehren, M., Blanke, C. D., Van den Abbeele, A. D., Eisenberg, B., Roberts, P. J., et al. (2002). Efficacy and safety of imatinib mesylate in advanced gastrointestinal stromal tumors. N. Engl. J. Med. 347, 472-480.

El-Badry, O. M., Romanus, J. A., Helman, L. J., Cooper, M. J., Rechler, M. M., and Israel, M. A. (1989). Autonomous growth of a human neuroblastoma cell line is mediated 
by insulin-like growth factor II. $J$. Clin. Invest. 84, 829-839.

Friedrichs, N., Küchler, J., Endl, E., Koch, A., Czerwitzki, J., Wurst, P., etal. (2008). Insulinlikegrowthfactor-1receptoracts as a growth regulator in synovial sarcoma. J. Pathol. 216, 428-439.

Gansler, T., Furlaneto, R., Gramling, T. S., Robinson, K. A., Blocker, N., Buse, M. G., et al. (1989). Antibody to type I insulin like growth factor receptor inhibits growth of Wilms tumor in culture and in athymic mice. Am. J. Pathol. 135, 961-966.

Garofalo, C., Mancarella, C., Grilli, A. Manara, M. C., Astolfi, A., Marino, M. T., et al. (2012). Identification of common and distinctive mechanisms of resistance to different anti-IGF$1 \mathrm{R}$ agents in Ewing's sarcoma. Mol. Endocrinol. 26, 1603-1616.

Geoerger, B., Brasme, J. F., DaudigeosDubus, E., Opolon, P., Venot, C., Debussche, L., et al. (2010). Antiinsulin-like growth factor 1 receptor antibody EM164 (murine AVE1642) exhibits anti-tumour activity alone and in combination with temozolomide against neuroblastoma. Eur. J. Cancer 46, 3251-3262.

Ghosh, P., Dahms, N. M., and Kornfeld, S. (2003). Mannose 6-phosphate receptors: new twists in the tale. Nat. Rev. Mol. Cell Biol. 4, 202-212.

Grimberg, A., and Cohen, P. (2000). Role of Insulin-like growth factors and their binding proteins in growth control and carcinogenesis. J. Cell. Physiol. 183, 1-9.

Houghton, P. J., Morton, C. L., Gorlick, R., Kolb, E. A., Keir, S. T., Reynolds, C. P., et al. (2010). Initial testing of a monoclonal antibody (IMC-A12) against IGF-1R by the Pediatric Preclinical Testing Program. Pediatr. Blood Cancer 54, 921-926.

Huang, F., Greer, A., Hurlburt, W., Han, X., Hafezi, X., Wittenberg, G. M., etal. (2009). The mechanisms of differential sensitivity to an insulin-like growth factor1 receptor inhibitor (BMS-536924) and rationale for combining with EGFR/HER2 inhibitors. Cancer Res. $69,169-170$.

Huang, F., Hurlburt, W., Greer, A., Reeves, K. A., Hillerman, S., Chang, H., et al. (2010). Differential mechanisms of acquired resistance to insulin-like growth factor-I receptor antibody therapy or to a smallmolecule inhibitor, BMS-754807, in a human rhabdomyosarcoma model. Cancer Res. 70, 7221-7231.

Huang, H. J., Angelo, L. S., Rodon, J., Sun, M., Kuenkele, K. P., Parsons, H. A., etal. (2011).
R1507, an anti-insulin-like growth factor-1 receptor (IGF1R) antibody, and EWS/FLI-1 siRNA in Ewing's sarcoma: convergence at the IGF/IGFR/Akt axis. PLoS ONE 6:e26060. doi 10.1371/journal.pone.0026060

Italiano, A., Chen, J., Zhang, L., Hajdu, M., Singer, S., DeMatteo, R. P. et al. (2012). Patterns of deregulation of insulin growth factor signaling pathway in paediatric and adult gastrointestinal stromal tumours. Eur. J. Cancer 48, 3215-3222.

Janeway, K. A., Albritton, K. H., Van Den Abbeele, A. D., D'Amato, G. Z., Pedrazzoli, P., Siena, S., et al. (2009). Sunitinib treatment in pediatric patients with advanced GIST following failure of imatinib. Pediatr. Blood Cancer 52, 767-771.

Janeway, K. A., Liegl, B., Harlow, A., Le, C., Perez-Atayde, A., Kozakewich, H., et al. (2007). Pediatric KIT wild-type and platelet-derived growth factor receptor alpha-wild-type gastrointestinal stromal tumors share KIT activation but not mechanisms of genetic progression with adult gastrointestinal stromal tumors. Cancer Res. 67, 9084-8.

Janeway, K. A., and Pappo, A. (2012). Treatment guidelines for gastrointestinal stromal tumors in children and young adults. J. Pediatr. Hematol. Oncol. 34(Suppl. 2), S69-S72.

Janeway, K. A., Zhu, M. J., Barretina, J., Perez-Atayde, A., Demetri, G. D., and Fletcher, J. A. (2010) Strong expression of IGF1R in pediatric gastrointestinal stromal tumors without IGF1R genomic amplification. Int. J. Cancer 127, 27182722.

Juergens, H., Daw, N. C., Geoerger, B., Ferrari, S., Villarroel, M., Aerts, I., et al. (2011). Preliminary efficacy of the anti-insulin-like growth factor type 1 receptor antibody figitumumab in patients with refractory Ewing sarcoma. J. Clin. Oncol. 29, 4534-4540.

Kalapurakal, J. A., Dome, J. S., Perlman, E. J., Malogolowkin, M., Haase, G. M., Grundy, P., et al. (2004). Management of Wilms Tumor: current practice and future goals. Lancet Oncol. 5, 37-46.

Kappel, C. C., VelezYanguas, M. C., Hirschfeld, S., and Helman, L, J. (1994). Human osteosarcoma cell lines are dependent on insulin-like growth factor I for in vitro growth. Cancer Res. 54, 2803-2807.

Kim, S. Y., Wan, X., and Helman, L. J. (2009). Targeting IGF-1R in the treatment of sarcomas: past, present and future. Bull. Cancer 96, E52-E60.
Kolb, E. A., Gorlick, R., Houghton, P. J., Morton, C. L., Lock, R., Carol, H., et al. (2008). Initial testing (stage1) of a monoclonal antibody (SCH 717454) against the IGF-1 receptor by the pediatric preclinical testing program. Pediatr. Blood Cancer 50, 1190-1197.

Kolb, E. A., Gorlick, R., Lock, R., Carol, H., Morton, C. L., Keir, S. T., et al. (2011). Initial testing (Stage I) of the IGF-1 receptor inhibitor BMS- 754807 by the pediatric preclinical testing program. Pediatr. Blood Cancer 56, 595-603.

Kolb, E. A., Gorlick, R., Maris, J. M., Keir, S. T., Morton, C. L. $\mathrm{Wu}$, J., et al. (2012). Combination testing (Stage2) of the Anti-IGF1receptorantibodyIMC-A12 with rapamycin by the pediatric preclinical testing program. Pediatr. Blood Cancer 58, 729-735.

Kolb, E. A., Kamara, D., Zhang, W., Lin, J., Hingorani, P., Baker, L., et al. (2010). R1507, a fully human monoclonal antibody targeting IGF-1R, is effective alone and in combination with rapamycin in inhibiting growth of osteosarcoma xenografts. Pediatr. Blood Cancer 55, 67-75.

Lee, G. Y., and Rechler, M. M (1996). Proteolysis of insulin-like growth factor (IGF)-binding protein3 (IGFBP-3) in 150-kilodalton IGFBP complexes by a cation-dependent protease activity in adult rat serum promotes the release of bound IGF-I. Endocrinology 137, 2051-2058.

Maki, R. G. (2010). Small is beautiful: insulin-like growth factors and their role in growth, development, and cancer. J. Clin. Oncol. 28, 49854995.

Maki, R. G. (2012). "VEGFR and IGF1R inhibitors in sarcoma therapy," in Oral presentation at ASCO 2012, Chicago.

Malempati, S., Weigel, B., Ingle, A. M., Ahern, C. H., Carroll, J. M., Roberts, C. T., et al. (2012). Phase I/II trial and pharmacokinetic study of cixutumumab in pediatric patients with refractory solid tumors and Ewing sarcoma: a report from the Children's Oncology Group. J. Clin. Oncol. 30, 256-262.

Maris, J. (2010). Recent advances in neuroblastoma. N. Engl. J. Med. 362 , 2202-2211.

Martins, A. S., Mackintosh, C., Martín, D. H., Campos, M., Hernández, T., Ordóñez, J. L., etal. (2006). Insulin like growth factor I receptor pathway inhibition by ADW742, alone or in combination with imatinib, doxorubicin, or vincristine, is a novel therapeutic approach in Ewing tumor. Clin. Cancer Res. 12, 3532 3540.

Mirabello, L., Troisi, R. J., and Savage, S. A. (2009). Osteosarcoma incidence and survival rates from 1973 to 2004: data from the Surveillance, Epidemiology, and End Results Program. Cancer 115, 1531-1543.

Naing, A., LoRusso, P., Fu, S., Hong, D. S., Anderson, P., Benjamin, R. S., et al. (2012). Insulin growth factorreceptor (IGF-1R) antibody cixutumumab combined with the mTOR inhibitor temsirolimus in patients with refractory Ewing's sarcoma family tumors. Clin. Cancer Res. 18, 2625-2631.

Natrajan, R., Reis-Filho, J. S., Little, S. E., Messahel, B., Brundler, M. A., Dome, J. S., et al. (2006). Blastemal expression of type I inslin-like growth factor receptor in Wilms tumors is driven by increased copy number and correlates with relapse. Cancer Res. 66, 11148-11155.

Northcott, P. A., Jones, D. T., Kool, M., Robinson, G. W., Gilbertson, R. J., Cho, Y. J., et al. (2012). Medulloblastomics: the end of the beginning. Nat. Rev. Cancer 12, 818-834.

Olmos, D., Postel-Vinay, S., Molife, L. R., Okuno, S. H., Schuetze, S. M., Paccagnella, M. L., et al. (2010). Safety, pharmacokinetics, and preliminary activity of the anti-IGF-1R antibody figitumumab (CP-751,871) in patients with sarcoma and Ewing's sarcoma: a phase 1 expansion cohort study. Lancet Oncol. 11, 129-135.

Pappo, A. S., Patel, S. R., Crowley, J., Reinke, D. K., Kuenkele, K. P., Chawla, S. P., et al. (2011). R1507, a monoclonal antibody to the insulin-like growth factor-1 receptor, in patients with recurrent or refractory Ewing sarcoma family of tumors: results of a phase II Sarcoma Alliance for Research Through Collaboration study. J. Clin. Oncol. 29, 45414547.

Paugh, B. S., Qu, C., Jones, C., Liu, Z., Adamowicz-Brice, M., Zhang, J., et al. (2010). Integrated molecular genetic profiling of pediatric highgrade gliomas reveals key differences with the adult disease. J. Clin. Oncol. 28, 3061-3068.

Petricoin, E. F. III, Espina, V., Araujo, R. P., Midura, B., Yeung, C., Wan, X., etal. (2007). Phosphoprotein pathway mapping: Akt/mammalian target of rapamycin activation is negatively associated with childhood rhabdomyosarcoma survival. Cancer Res. 67, 3431-3440.

Pollack, M. (2008). Insulin and insulinlike growth factor signalling in neoplasia. Nat. Rev. Cancer 8, 915-928. 
Potratz, J. C., Saunders, D. N., Wai, D. H., Ng, T. L., McKinney, S. E., Carboni, J. M., et al. (2010). Synthetic lethality screens reveal RPS6 and MST1R as modifiers of insulin-like growth factor-1 receptor inhibitor activity in childhood sarcomas. Cancer Res. 70, 8770-8781.

Prakash, S., Sarran, L., Socci, N., DeMatteo, R.P., Eisenstat, J., Greco, A. M., et al. (2005). Gastrointestinal stromal tumors in children and young adults: a clinicopathologic, molecular, and genomic study of 15 cases and review of the literature. $J$. Pediatr. Hematol. Oncol. 27, 179-187.

Prieur, A., Tirode, F., Cohen, P., and Delattre, O. (2004). EWS/FLI1 silencing and gene profiling of Ewing cells reveal downstream oncogenic pathways and a crucial role for repression of insulin-like growth factor binding protein 3. Mol. Cell. Biol. 24, 7274-7283.

Quek, R., Wang, Q., Morgan, J. A., Shapiro, G. I., Butrynski, J. B., Ramaiya, N., et al. (2011). Combination $\mathrm{mTOR}$ and IGF-1R inhibition: phase I trial of everolimus and figitumumab in patients with advanced sarcomas and other solid tumors. Clin. Cancer Res. 17, 871-879.

Ricort, J. M., and Binoux, M. (2001). Insulin-like growth factor (IGF) binding protein-3 inhibits type 1 IGF receptor activation independently of its IGF binding affinity. Endocrinology 142, 108-113.

Rikhof, B., de Jong, S., Suurmeijer, A. J., Meijer, C., and van der Graaf, W. T. (2009). The insulin-like growth factor system and sarcomas. J. Pathol. 217, 469-482.

Schiffman, J. D., Hodgson, J. G., VandenBerg, S. R., Flaherty, P., Polley,
M. Y., Yu, M., et al. (2010). Oncogenic BRAF mutation with CDKN2A inactivation is characteristic of a subset of pediatric malignant astrocytomas. Cancer Res. 70, 512-519.

Schwartz, G. K., Tap, W. D., Qin, L. X., Livingston, M. B., Undevia, S. D., Chmielowski, B., et al. (2012). "The phase II Trial of the mTOR inhibitor temsirolimus and the IGF-1R inhibitor cixutumumab (IMC-A12) in patients with IGF$1 \mathrm{R}(+)$ and IGF-1R (-) bone and soft tissue sarcoma (STS)," in Annual Meeting of the American Society of Clinical Oncology, Chicago. Abstract 10003.

Scotlandi, K., Benini, S., Nanni, P., Lollini, P, L., Nicoletti, G., Landuzzi, L., et al. (1998). Blockage of insulin-like growth factor-I receptor inhibits the growth of Ewing's sarcoma in athymic mice. Cancer Res. $58,4127-4131$

Spillane, A. J., A’Hern, R., Judson, I. R., Fisher, C., and Thomas, J. M. (2000). Synovial sarcoma: a clinicopathologic, staging, and prognostic assessment. J. Clin. Oncol. 18, 3794-3803.

Sun, Y., Gao, D., Liu, Y., Huang, J., Lessnick, S., and Tanaka, S. (2006). IGF-2 is critical for tumorigenesis by synovial sarcoma oncoprotein SYT-SSX1. Oncogene 25, 1042 1052.

Tap, W. D., Demetri, G., Barnette, P., Desai, J., Kavan, P., Tozer, R., et al. (2012). Phase II study of ganitumab, a fully human anti-type-1 insulinlike growth factor receptor antibody, in patients with metastatic Ewing family tumors or desmoplastic small round cell tumors. J. Clin. Oncol. 30, 1849-1856.
Tolcher, A. W., Sarantopoulos, J., Patnaik, A., Papadopoulos, K., Lin, C. C., Rodon, J., et al. (2009). Phase I, pharmacokinetic, and pharmacodynamic study of AMG 479, a fully human monoclonal antibody to insulin-like growth factor receptor 1. J. Clin. Oncol. 27, 58005807.

van Golen, C. M., Schwab, T. S., Kim, B., Soules, M. E., Su Oh, S., Fung, K., et al. (2006). Insulin-like growth factor-I receptor expression regulates neuroblastoma metastasis to bone. Cancer Res. 66, 6570-6578.

Wan, X., Harkavy, B., Shen, N., Grohar, P., and Helman, L. J. (2007). Rapamycin induces feedback activation of Akt signaling through an IGF1R-dependent mechanism. Oncogene 26, 1932-1940.

Wang, Y. H., Han, X. D., Qiu, Y., Xiong, J., Yu, Y., Wang, B., et al. (2012) Increased expression of insulin-like growth factor-1 receptor is correlated with tumor metastasis and prognosis in patients with osteosarcoma. $J$. Surg. Oncol. 105, 235-243.

Weroha, S. J., and Haluska, P. (2012). The insulin-like growth factor system in cancer. Endocrinol. Metab. Clin. North Am. 41, 335-350.

Wojtalla, A., Salm, F., Christiansen, D. G., Cremona, T., Cwiek, P., Shalaby, T., etal. (2012). Novel agents targeting the IGF-1R/PI3K pathway impair cell proliferation and survival in subsets of medulloblastoma and neuroblastoma. PLoS ONE 7:e47109. doi: 10.1371/journal.pone. 0047109

Xiao, S. J., Pressey, J. G., and Barr, F. G. (2002). Molecular pathogenesis of rhabdomyosarcoma. Cancer Biol. Ther. 1, 97-104.
Xie, Y., Skytting, B., Nilsson, G., Brodin, B., and Larsson, O. (1999). Expression of insulin-like growth factor-1 receptor in synovial sarcoma: association with an aggressive phenotype. Cancer Res. 59, 35883591.

Yee, D., Favoni, R. E., Lebovic, G. S., Lombana, F., Powell, D. R., Reynolds, C. P., et al. (1990). Insulin-like growth factor I expression by tumors of neuroectodermal origin with the $\mathrm{t}(11 ; 22)$ chromosomal translocation. A potential autocrine growth factor. J. Clin. Invest. 86, 1806-1814.

Conflict of Interest Statement: The authors declare that the research was conducted in the absence of any commercial or financial relationships that could be construed as a potential conflict of interest.

Received: 07 December 2012; accepted: 10 January 2013; published online: 04 February 2013.

Citation: Wagner MJ and Maki RG (2013) Type 1 insulin-like growth factor receptor targeted therapies in pediatric cancer. Front. Oncol. 3:9. doi: 10.3389/ fonc.2013.00009

This article was submitted to Frontiers in Pediatric Oncology, a specialty of Frontiers in Oncology.

Copyright (c) 2013 Wagner and Maki. This is an open-access article distributed under the terms of the Creative Commons Attribution License, which permits use, distribution and reproduction in other forums, provided the original authors and source are credited and subject to any copyright notices concerning any thirdparty graphics etc. 